\title{
The impact of cirrhosis in patients undergoing cardiac surgery: a retrospective observational cohort study
}

\author{
Sheela Xavier, MBBS, MSc $\cdot$ Colleen M. Norris, PhD • Amanda Ewasiuk, MSc • \\ Demetrios J. Kutsogiannis, MD, MPH $\cdot$ Sean M. Bagshaw, MD, MSc $\cdot$ Sean van \\ Diepen, MD, MSc $\cdot$ Derek R. Townsend, MD · Jayan Negendran, MD, PhD • \\ Constantine J. Karvellas, MD, SM, FRCPC
}

Received: 20 January 2019/Revised: 12 July 2019/Accepted: 24 September 2019/Published online: 30 September 2019

(C) Canadian Anesthesiologists' Society 2019

\begin{abstract}
Purpose Patients with cirrhosis and concomitant coronary/valvular heart disease present a clinical dilemma. The therapeutic outcome of major cardiac surgery is significantly poorer in patients with cirrhosis compared with patients without cirrhosis. To address this, we aimed to identify associations between the severity of cirrhosis and post-cardiac surgical outcomes.

Methods $A$ historical cohort analysis of patients undergoing cardiac surgery at the University of Alberta Hospital from January 2004 to December 2014 was used to identify and propensity score-match 60 patients with cirrhosis to 310 patients without cirrhosis. The
\end{abstract}

Electronic supplementary material The online version of this article (https://doi.org/10.1007/s12630-019-01493-7) contains supplementary material, which is available to authorized users.

S. Xavier, MBBS, MSc · A. Ewasiuk, MSc .

D. J. Kutsogiannis, MD, MPH - S. M. Bagshaw, MD, MSc Department of Critical Care Medicine, Faculty of Medicine and Dentistry, University of Alberta, Edmonton, AB T6G 2X8, Canada

C. M. Norris, $\mathrm{PhD}$

Faculty of Nursing, University of Alberta, Edmonton, AB, Canada

S. van Diepen, MD, MSc

Department of Critical Care Medicine, Faculty of Medicine and Dentistry, University of Alberta, Edmonton, AB T6G 2X8,

Canada

Division of Cardiology, University of Alberta, Edmonton, AB, Canada

D. R. Townsend, MD

Department of Critical Care Medicine, Faculty of Medicine and Dentistry, University of Alberta, Edmonton, AB T6G 2X8,

Canada relationships between cirrhosis and i) mortality, ii) postoperative complications, and iii) requirement of healthcare resources were evaluated.

Results Ten-year mortality was significantly higher in cirrhotic patients compared with propensity score-matched non-cirrhotic patients $(40 \%$ vs $20 \%$; relative risk [RR], 2.0; 95\% confidence interval [CI], 1.3 to $2.9 ; P=0.001$ ). Cirrhotic patients had more complications (63\% vs 48\%; $R R, 1.3 ; 95 \%$ CI, 1.05 to 1.7; $P=0.02)$, longer median [interquartile range (IQR)] intensive care unit stays (5 [311] vs 2 [1-4] days; $P<0.001)$, time on mechanical ventilation (median [IQR] 2 [1-5] vs 1 [0.5-1.2] days; $P<$ $0.001)$ and more frequently required renal replacement therapy $(15 \%$ vs $6 \%$; RR, 2.5; $95 \% C I, 1.2$ to $5.2 ; P=$ $0.02)$ postoperatively. After adjusting for other covariates, presence of cirrhosis (adjusted odds ratio, 2.2; 95\% CI, 1.1

Department of Anesthesiology and Pain Medicine, University of Alberta, Edmonton, AB, Canada

J. Negendran, MD, $\mathrm{PhD}$

Division of Cardiac Surgery, University of Alberta, Edmonton, $\mathrm{AB}$, Canada

C. J. Karvellas, MD, SM, FRCPC ( $₫)$

Department of Critical Care Medicine, Faculty of Medicine and Dentistry, University of Alberta, Edmonton, AB T6G 2X8,

Canada

e-mail: dean.karvellas@ualberta.ca

Division of Gastroenterology (Liver Unit), University of Alberta, Edmonton, AB T6G 2X8, Canada 
to 4.1) and intraoperative transfusion (adjusted odds ratio, 3.2; $95 \%$ CI, 1.6 to 6.3) were independently associated with increased mortality.

Conclusion Despite having low median model for endstage liver disease scores, this small series of cirrhotic patients undergoing cardiac surgery had significantly higher mortality rates and required more organ support postoperatively than propensity score-matched noncirrhotic patients. Impact de la cirrhose chez les patients subissant une chirurgie cardiaque : une étude de cohorte observationnelle et rétrospective

\section{Résumé}

Objectif Les patients atteints de cirrhose et de coronaropathie et/ou valvulopathie concomitante posent un dilemme clinique. Le pronostic thérapeutique d'une chirurgie cardiaque majeure est significativement moins bon chez les patients atteints de cirrhose comparativement aux patients ne souffrant pas de cette condition. Nous avons par conséquent tenté d'identifier les associations entre la sévérité de la cirrhose et l'évolution post-chirurgie cardiaque.

Méthode Une analyse de cohorte historique des patients ayant subi une chirurgie cardiaque à l'Hôpital de l'Université de l'Alberta entre janvier 2004 et décembre 2014 a été utilisée afin d'identifier et d'apparier par score de propension 60 patients atteints de cirrhose à 310 patients ne souffrant pas de cirrhose. Les liens entre la cirrhose et i) la mortalité, ii) les complications postopératoires, et iii) les besoins en ressources de soins de santé ont été évalués.

Résultats La mortalité à dix ans était significativement plus élevée chez les patients cirrhotiques comparativement aux patients non cirrhotiques appariés par score de propension (40 \% vs $20 \%$; risque relatif [RR], 2,0; intervalle de confiance [IC] $95 \%, 1,3$ à 2,9; $P=0,001$ ). Les patients cirrhotiques ont subi davantage de complications (63\% vs $48 \%$; RR, 1,3; IC $95 \%, 1,05$ à 1,7; $P=0,02)$, des séjours médians [écart interquartile (ÉIQ)] plus longs à l'unité de soins intensifs (5 [3-11] vs 2 [1-4] jours; $P<0,001)$, un temps médian sous ventilation mécanique plus long ([ÉIQ] 2 [1-5] vs 1 [0,5-1,2] jours; $P$ $<0,001)$ et ont nécessité un traitement substitutif de l'insuffisance rénale plus fréquemment (15\% vs $6 \%$; RR, 2,5; IC $95 \%, 1,2$ à 5,2; $P=0,02)$ en période postopératoire. Après avoir ajusté les résultats pour tenir compte des autres covariables, la présence de cirrhose (rapport de cotes ajusté, 2,2; IC 95\%, 1,1 à 4,1) et de transfusion peropératoire (rapport de cotes ajusté, 3,2; IC $95 \%, 1,6$ à 6,3) était indépendamment associée à une mortalité accrue.

Conclusion Malgré le fait qu'elle ne résultait qu'en un modèle médian bas pour les scores d'insuffisance hépatique terminale, cette petite série de patients cirrhotiques subissant une chirurgie cardiaque a démontré des taux de mortalité significativement plus élevés et un besoin accru de support des fonctions physiologiques en période postopératoire par rapport aux patients non cirrhotiques appariés par score de propension.

Cardiac surgery in patients with end-stage liver disease (cirrhosis) presents a significant challenge. ${ }^{1}$ Previous uncontrolled studies have shown that cirrhotic patients have high rates of postoperative morbidity and mortality. ${ }^{2-4}$ Nutritional compromise, immune system dysfunction, coagulopathy, acute kidney injury, and cirrhotic cardiomyopathy have been postulated to explain this. ${ }^{1,2,5}$ Surgeons traditionally have been hesitant to perform elective cardiac surgery in patients with advanced liver disease that may preclude future liver transplantation eligibility and long-term survival. ${ }^{6,7}$

It has been empirically agreed that cardiac surgery is contraindicated in patients with end-stage liver disease because of high mortality after cardiac surgery. Postcardiac surgical outcomes in cirrhotic patients have been shown to be poorer in patients with high Child-TurcottePugh (CTP) and model for end-stage liver disease (MELD) scores. In existing practice, CTP class B/C and MELD score $>12-14$ were associated with high early and late mortality following cardiac surgery using cardiopulmonary bypass in patients with cirrhosis. ${ }^{8-14}$ Identification and careful evaluation of risk factors that predict the outcomes following cardiac surgery may reduce serious postsurgical complications.

Accordingly, in this study we aimed to describe (i) survival following cardiac surgery, (ii) pre/perioperative factors that were independently associated with increased mortality, and (iii) the association between severity of liver disease and post-cardiac surgical outcomes.

\section{Methods}

Study setting and population

Our cohort included 370 patients who were greater than 17 $\mathrm{yr}$ of age who were admitted to the adult cardiovascular surgical intensive care unit (CVICU) following cardiac surgery with cardiopulmonary bypass (CPB) from January 2004 to December 2014 at the Mazankowski Alberta Heart Institute, University of Alberta. Patients undergoing heart transplantation and pediatric patients were excluded (Figure). 
Data sources and collection

Data were collected from the APPROACH database (Alberta Provincial Project for Outcomes Assessment in Coronary Heart Disease). This registry has statistics on all cardiac patients undergoing any cardiac procedures in Alberta, Canada, since $1995 .{ }^{15,16}$ It provides detailed patient information which includes demographics, medical, surgical, and postoperative clinical parameters. Preoperative and intraoperative variables were reviewed, and postoperative variables and complications were extracted using the Society of Thoracic Surgeons database definitions. Mortality information was obtained via quarterly data linkage with the Alberta Bureau of Vital Statistics. ${ }^{17}$

Patients were defined as having cirrhosis by radiological evidence (cirrhotic nodular liver on ultrasound, reversal of flow), pathological evidence (scarring/fibrosis on liver biopsy), or evidence of complications of cirrhosis such as ascites, esophageal/gastric varices, hepatic encephalopathy, or spontaneous bacterial peritonitis in the patient record. Coding of the cirrhosis diagnosis was in agreement with the International Classification of Diseases-9-clinical modification. Data on etiology and complications of cirrhosis, MELD, comorbidities before surgery, and relevant clinical laboratory parameters during, before, and after surgery for 60 cirrhotic patients were abstracted from medical charts. The MELD score was calculated according to the 2016 United Network for Organ Sharing/ Organ Procurement and Transplantation Network policy. ${ }^{18,19}$ This study was approved by the University of Alberta Health Research Ethics Board (Pro00038965).

\section{Outcomes}

The primary outcomes of interest for our study were oneyear, five-year, and ten-year mortalities. Our secondary outcomes of interest included in-hospital mortality, a composite of major postoperative complications, individual complications including cardiac tamponade, atrial fibrillation, prolonged mechanical ventilation $(>24$ hr), pleural effusion, acute kidney injury, nosocomial infection, gastrointestinal hemorrhage or ischemia, delirium, resuscitated cardiac arrest, and reoperation. Other secondary outcomes included health resource utilization, which included chest tube insertion, CVICU length of stay, and renal replacement therapy.

\section{Statistical analyses}

Statistical analysis was carried out using Stata version 13.0 for Windows (StataCorp LP, College Station, TX, USA). Continuous variables were described as median [interquartile range (IQR)] and mean (standard deviation) depending on the results of normality testing. Univariate analyses for categorical variables were analyzed with conditional logistic regression. Continuous variables were tested with the Wilcoxon sign rank test for non-normally distributed variables and the paired $t$ test for normally distributed variables. We performed a propensity scorematched analysis of cirrhotic and non-cirrhotic patients to obtain a comparable distribution of demographics, comorbidities, preoperative, operative, and postoperative clinical variables using the Rosenbaum and Rubin propensity score-matching method. ${ }^{20}$ The propensity score was calculated as the probability of having cirrhosis on the observed baseline characteristics. This method allows for a high number of confounding variables and hence was used to create strata of subjects who were propensity matched, meaning exposure (i.e., cirrhosis) would be conditionally independent of measured baseline covariates. The propensity score was calculated using logistic regression.

Age, sex, cerebrovascular disease, congestive heart failure, chronic obstructive pulmonary disease, gastrointestinal disease, renal disease, diabetes mellitus, dialysis, hypertension, hyperlipidemia, malignancy, peripheral vascular disease, present/previous smoker, previous myocardial infarction, previous coronary artery bypass surgery, previous percutaneous coronary intervention, priority of surgery, incidence of surgery, and type of cardiac surgery were the variables included in the model. These variables were selected based on known clinical or statistical differences between the unmatched cohorts. Charlson comorbidity index (CCI) was not included in the propensity matching (refer to eAppendix 1 as Electronic Supplementary Material [ESM]). Greedy matching techniques were applied to select the patients in the non-cirrhotic group to cirrhotic by matching the patients with the nearest propensity score (i.e., within three decimal places of the propensity score) for each case. Overlap of propensity scores between patients in both cohorts were evaluated using histograms, $\chi 2$ values, and probability values. Differences in baseline factors between groups were calculated before and after propensity scorematching adjustment to assess balance. ${ }^{21}$ No covariate exhibited a large imbalance (standardized difference $>$ 0.25). After the match, conditional logistic regression and Wilcoxon sign rank tests were used to determine if the intraoperative variables that were not accounted for in the propensity score matching were statistically significant between cirrhotic and non-cirrhotic patients that underwent cardiac surgery.

To adjust for other covariates not accounted for in propensity matching, multivariable conditional logistic regression analysis was used to determine the association 
between cirrhosis and mortality. Covariates were included based on a $P$ value $<0.10$ from univariable analysis. After exclusion of collinear, non-significant, and non-clinically important variables, the final model was built using a purposeful selection method. Results were reported as unadjusted and adjusted odds ratio (aOR) with 95\% confidence interval $(\mathrm{CI})$ and $P$ value $<0.05$. The final model performance was estimated using the area under the receiver operator curve (AUROC). Kaplan-Meier survival analysis was used to evaluate long-term survival time stratified between cirrhotic and non-cirrhotic patients (log rank test).

\section{Results}

In our final study population, a total of 60 cirrhotic patients were propensity score-matched, in a ratio of approximately $1: 5$, to 310 non-cirrhotic patients undergoing cardiac surgery. The cirrhotic and non-cirrhotic patient cohorts were well balanced for age, sex, body mass index, and clinical and preoperative variables (Table 1). Operative variables shown in Table 2 were also balanced between the two patient cohorts in terms of surgical priority, procedures, and incidence. Cirrhotic patients had significantly longer median [IQR] CPB time (128 [99200] vs 116 [83-161] min; $P=0.02$ ) and were more likely to receive two or more units of blood (57\% vs $38 \%$; relative risk [RR], $1.5 ; 95 \% \mathrm{CI}, 1.2$ to $1.9 ; P=0.03$ ) or median [IQR] transfusions (58\% vs 43\%; RR, 1.4; $95 \%$ CI, 1.05 to $1.73 ; P=0.03$ ) during surgery (red blood cell, $1[0-3]$ vs 0 [0-1]; $P<0.001$; fresh frozen plasma, 0 [0-2] vs 0 [0-0]; $P=0.003$; and platelets, $0[0-1]$ vs $0[0-1] ; P=0.02$ ).

\section{Clinical outcomes}

The mortality rates for one year $(22 \%, n=13$ vs $8 \%, n=$ 24; RR, 2.8; $95 \% \mathrm{CI}, 1.5$ to $5.2 ; P=0.002$ ), five years (37\%, $n=22$ vs $18 \%, n=55$; RR, 2.1; 95\% CI, 1.4 to 3.1; $P=0.001)$ and ten years of follow-up $(40 \%, n=24 \mathrm{vs} 20 \%$, $n=63$; RR, $2 ; 95 \%$ CI, 1.3 to $2.9 ; P=0.001)$ in patients undergoing cardiac surgery were significantly higher in cirrhotic patients compared with propensity score-matched non-cirrhotic controls (see Table 3). Stated otherwise, patients with cirrhosis had 41 deaths per 1,000 patientyears compared with 28 deaths per 1,000 patient-years of follow-up in non-cirrhotics. In-hospital mortality was also higher in cirrhotic patients compared with controls (15\% vs $5 \%$ in controls, RR, 3.1; 95\% CI, 1.4 to $6.8 ; P=0.05$ ). Nevertheless, there was no significant difference between cirrhotic patients and non-cirrhotic patients in terms of 30day mortality. A composite of major postoperative complications (eAppendix 2 as ESM) occurred more commonly in patients with liver cirrhosis $v s$ controls (63\% vs $48 \%$, RR, 1.3 ; $95 \%$ CI, 1.05 to $1.7 ; P=0.02$ ). Cirrhotic patients were significantly more likely to develop cardiac arrest (8.3\% vs $1.3 \%$; RR, 6.5 ; $95 \%$ CI, 1.8 to 23.4 ; $P=0.006)$, pneumonia ( $23.3 \%$ vs $9.7 \%$; RR, $2.4 ; 95 \% \mathrm{CI}$, 1.4 to $4.3 ; P=0.004)$, pleural effusion $(15 \%$ vs $5 \%$; RR, $2.9 ; 95 \% \mathrm{CI}, 1.4$ to $6.3 ; P=0.009)$, and acute kidney injury (21.7\% vs $7.7 \%$; RR, 2.8; $95 \%$ CI, 1.5 to $5.2 ; P=0.001$ ). They were also more likely to require chest tube insertion (10\% vs 3\%; RR, 3.1; 95\% CI, 1.2 to $8.2 ; P=0.02$ ), prolonged (more than $24 \mathrm{hr}$ ) mechanical ventilation $(33 \%$ vs $22 \%$; RR, $1.5 ; 95 \% \mathrm{CI}, 1.01$ to $2.3 ; P=0.05$ ), and renal replacement therapy ( $15 \%$ vs $6 \%$; RR, 2.5 ; $95 \% \mathrm{CI}, 1.2$ to 5.2; $P=0.02$ ) postoperatively. Cirrhotic patients remained in the intensive care unit (ICU) postoperatively for significantly longer median [IQR] days than noncirrhotic controls $(5$ [3-11] vs $2[1-4]$ days; $P<0.001)$. Cumulative survival amongst cirrhotic patients at one, five, and 10 years was significantly lower than controls (log rank, 0.01)

Multivariable conditional logistic regression was performed to adjust for potential confounders in the final model. The results of this analysis are provided in Table 4 . After adjusting other covariates in the model, cirrhosis (aOR, 2.2; 95\% CI, 1.1 to 4.1 ), and any intraoperative transfusions (aOR, 3.2; 95\% CI, 1.6 to 6.3) were independently associated with increased overall mortality. The final model performance was estimated by AUROC and was 0.71 .

Predictors of survival in cirrhotic patients undergoing cardiac surgery

Univariable analysis was performed on 60 patients with cirrhosis to compare the results between survivors and nonsurvivors (eAppendix 2 as ESM). Overall, the median [IQR] MELD score in these cirrhotic patients was low (11 [9-18]), indicating that cardiac surgery was performed in patients with less advanced liver disease. In comparing survivors, non-survivors were significantly older [mean (SD) years, 59.5 (12.5) vs 50.7 (13.0); $P=0.01]$ and had a higher prevalence of preoperative ascites $(45.8 \%$ vs $13.9 \%$; RR, 1.3 ; $95 \%$ CI, 1.05 to $1.7 ; P=0.008$ ), a higher median [IQR] MELD score (12.1 [8.6-20.3] vs 8.8 [4.4-15.4]; $P=$ $0.03)$, a higher median [IQR] CCI (5 [3-7] vs 2 [1-3]; $P<$ 0.001 ), and a higher median [IQR] creatinine (108 [83144] vs 79 [58-93]; $P<0.001)$ preoperatively. In addition, they had significantly longer median [IQR] ICU days (10.5 [4.5-25] vs 4 [2-5]; $P<0.001)$ and in-hospital days (32 [18-51] vs 9 [6-14]; $P<0.001)$ and required more organ support, which included vasopressors (87.5\% vs 61.1\%; RR, $1.4 ; 95 \%$ CI, 1.06 to $1.9 ; P=0.03$ ), median [IQR] days of mechanical ventilation (5 [2-18] vs 2 [1-2]; $P=0.004)$, 
Table 1 Clinical and preoperative characteristics of cirrhotic patients and non-cirrhotic controls

\begin{tabular}{|c|c|c|c|c|c|c|}
\hline Variables & $n$ & Cirrhosis & $n$ & Non-cirrhosis & $P$ value & Standardized difference \\
\hline Age & 60 & $54(13.4)$ & 310 & $52.5(17)$ & 0.44 & 0.15 \\
\hline Male sex & 60 & $42(70)$ & 310 & $218(70)$ & 0.91 & 0.14 \\
\hline BMI & 45 & $27.4[24-32]$ & 236 & $28.4[25-33]$ & 0.13 & \\
\hline \multicolumn{7}{|l|}{ Medical history } \\
\hline Hypertension & 60 & $35(58.3)$ & 310 & $176(56.8)$ & 0.82 & 0.03 \\
\hline Dyslipidemia & 60 & $38(63.3)$ & 310 & $186(60)$ & 0.61 & 0.09 \\
\hline Type 2 diabetes & 60 & $16(26.7)$ & 310 & $78(25.2)$ & 0.79 & 0.08 \\
\hline Prior MI & 60 & $22(36.7)$ & 310 & $105(33.8)$ & 0.69 & 0.06 \\
\hline Prior PCI & 60 & $4(6.7)$ & 310 & $22(7.1)$ & 0.92 & -0.03 \\
\hline Prior CABG & 60 & $3(5)$ & 310 & $10(3.2)$ & 0.52 & 0.08 \\
\hline Heart failure & 60 & $16(26.7)$ & 310 & 67 (21.6) & 0.41 & 0.09 \\
\hline NYHA class & & & & & 0.80 & \\
\hline Class 1 & 60 & $6(10)$ & 310 & $16(5.2)$ & & \\
\hline Class 2 & 60 & $5(8.3)$ & 310 & $44(14.2)$ & & \\
\hline Class 3 & 60 & $9(15)$ & 310 & $36(11.7)$ & & \\
\hline Class 4 & 60 & $3(5)$ & 310 & $24(7.7)$ & & \\
\hline Not entered & 60 & $37(61.7)$ & 310 & $190(61.3)$ & & \\
\hline Current smoker & 60 & $26(43.3)$ & 310 & $127(41.2)$ & 0.84 & 0.02 \\
\hline Preoperative renal failure & 60 & $3(5)$ & 310 & $13(4.2)$ & 0.82 & \\
\hline CCI & 60 & $3[1-5]$ & 310 & $2[1-4]$ & 0.11 & \\
\hline MELD & 38 & $11[9-18]$ & - & - & - & \\
\hline \multicolumn{7}{|l|}{ Preoperative investigations } \\
\hline \multicolumn{5}{|c|}{ Extent of coronary artery disease $(>75 \%)$} & 0.53 & \\
\hline One or two VD & 60 & $6(10)$ & 310 & $30(9.7)$ & & \\
\hline Three VD & 60 & $13(21.7)$ & 310 & $61(19.7)$ & & \\
\hline Left main artery & 60 & $11(18.3)$ & 310 & $54(17.4)$ & & \\
\hline Normal angiogram & 60 & $10(16.7)$ & 310 & $65(21)$ & & \\
\hline Not available & 60 & $15(25)$ & 310 & $83(26.8)$ & & \\
\hline$<50 \%$ & 60 & $5(8.3)$ & 310 & $17(5.5)$ & & \\
\hline LVEF, \% & & & & & 0.22 & \\
\hline$>50 \%$ & 60 & $9(27.3)$ & 310 & $81(26.13)$ & & \\
\hline$>35-50 \%$ & 60 & $8(24.2)$ & 310 & $44(14.2)$ & & \\
\hline$>20-34 \%$ & 60 & $2(6.1)$ & 310 & $12(3.9)$ & & \\
\hline$<20 \%$ & 60 & $1(3)$ & 310 & 0 & & \\
\hline Not available & 60 & $37(61.7)$ & 310 & $173(55.8)$ & & \\
\hline
\end{tabular}

Age is presented as mean (standard deviation). Other values are presented as median [interquartile range] and proportion (percentage). BMI = body mass index; $\mathrm{CABG}=$ coronary artery bypass graft $\mathrm{CCI}=$ Charlson comorbidity index; $\mathrm{LVEF}=$ left ventricular ejection fraction; $\mathrm{MI}=$ myocardial infarction; MELD = model for end-stage liver disease; NYHA = New York Heart Association; PCI = percutaneous coronary intervention; $\mathrm{VD}=$ vessel disease.

and renal replacement therapy $(45.8 \%$ vs $2.8 \%$; RR, 16.5 ; 95\% CI, 2.3 to $119.6 ; P<0.001)$ compared with survivors. Causes of death for the nine cirrhotic patients who died in hospital post-cardiac surgery were multiorgan failure $(n=$ $3)$, hemorrhage/bleeding $(n=2)$, neurological failure $(n=$ $2)$, postoperative surgical complications $(n=1)$, and intraabdominal sepsis $(n=1)$.

\section{Discussion}

Key findings

In this propensity score-matched cohort analysis of patients undergoing cardiac surgery, the ten-year mortality was significantly higher in cirrhotic patients compared with 
Table 2 Operative variables in patients with and without cirrhosis

\begin{tabular}{|c|c|c|c|c|c|c|}
\hline Variables: & $n$ & Cirrhosis & $n$ & Non-cirrhosis & $P$ value & Standardized difference \\
\hline \multicolumn{7}{|l|}{ Operative variables } \\
\hline Surgical priority & & & & & 0.26 & \\
\hline Emergent & 60 & $6(10)$ & 310 & $25(8.1)$ & & 0.05 \\
\hline Urgent in hospital & 60 & $27(45)$ & 310 & $130(42)$ & & 0.09 \\
\hline Urgent out of hospital & 60 & $22(36.7)$ & 310 & $113(36.5)$ & & -0.02 \\
\hline Non-urgent out of hospital & 60 & $5(8.3)$ & 310 & $42(13.6)$ & & 0.01 \\
\hline Surgical incidence & & & & & 0.54 & \\
\hline First operation & 60 & $48(80)$ & 310 & $240(77.7)$ & & \\
\hline Second operation & 60 & $11(18.3)$ & 310 & $58(18.8)$ & & 0.26 \\
\hline Third or greater & 60 & $1(1.7)$ & 310 & $11(3.6)$ & & -0.03 \\
\hline Surgery & & & & & 0.46 & \\
\hline CABG & 60 & $25(41.7)$ & 310 & $119(38.4)$ & & \\
\hline $\mathrm{CABG}+$ valve & 60 & $7(11.7)$ & 310 & $27(8.7)$ & & \\
\hline Valve & 60 & $26(43.3)$ & 310 & $148(47.7)$ & & \\
\hline Miscellaneous & 60 & $2(3.3)$ & 310 & $16(5.2)$ & & \\
\hline \multicolumn{7}{|l|}{ Intraoperative variables } \\
\hline Cardiopulmonary bypass time & 60 & 128 [99-200] & 310 & $116[83-161]$ & 0.02 & \\
\hline Aortic cross-clamp time & 60 & $82[48-115]$ & 310 & $75[46-115]$ & 0.14 & \\
\hline Any transfusion & 60 & $35(58)$ & 310 & $134(43)$ & 0.03 & \\
\hline Number of blood products & & & & & 0.03 & \\
\hline One & 60 & $1(2)$ & 310 & $16(5)$ & & \\
\hline Two or more & 60 & $34(57)$ & 310 & $118(38)$ & & \\
\hline No transfusion & 60 & $25(41)$ & 310 & $176(57)$ & & \\
\hline Intraoperative $\mathrm{RBC}$ & 60 & $1[0-3]$ & 310 & $0[0-1]$ & 0.0001 & \\
\hline Intraoperative FFP & 60 & $0[0-2]$ & 310 & $0[0-0]$ & 0.003 & \\
\hline Intraoperative cryoprecipitate & 60 & $0[0-0]$ & 310 & $0[0-0]$ & 0.08 & \\
\hline Intraoperative platelet & 60 & $0[0-1]$ & 310 & $0[0-1]$ & 0.02 & \\
\hline
\end{tabular}

Values presented as median [interquartile range] and proportion (percentage). CABG = coronary artery bypass graft; $\mathrm{FFP}=$ fresh frozen plasma; $\mathrm{RBC}=$ red blood cell.

non-cirrhotic controls. Patients with cirrhosis suffered more postoperative complications, required significantly longer stays in the ICU and hospital, and had increased requirements for postoperative organ support. Cirrhosis was also independently associated with increased postcardiac surgical mortality.

Comparison with previous literature

Previous observational studies have shown that cirrhotic patients undergoing cardiac surgery have increased mortality. A 2010 systematic review of nine retrospective analyses of 12-44 patients with cirrhosis undergoing a wide range of cardiac operations showed that the overall mortality was $17 \%$ with MELD scores of $>13 .^{22}$ In a retrospective analysis, Vanhuyse et al. reported that the inhospital mortality rate was $26 \%$ in 34 patients with a mean
MELD score of 12. Both CTP and MELD scores were associated with an increased postoperative mortality. ${ }^{23}$ In a retrospective cohort study from 2013, Morimoto et al. reported that the number of deaths in hospital following cardiac surgery in 32 patients with liver disease was $15.6 \%$ with an average mean (standard deviation) MELD score of 11.5 (5.1). ${ }^{24}$ A prospective study in the same year reported $12 \%$ mortality immediately after cardiac surgery in 58 cirrhotic patients with mean MELD scores of $18 .^{25}$ Both studies affirmed the usefulness of MELD in association with in-hospital mortality. In 2014, Lin and colleagues reported that 55 cirrhotic patients who underwent cardiac surgery over a 19-year period had an in-hospital mortality rate of $16.4 \%$ and that preoperative serum bilirubin prior to coronary artery bypass graft (CABG) was independently associated with mortality. Nevertheless, the MELD score failed to predict the overall mortality. ${ }^{26}$ Despite low 
Table 3 Postoperative outcomes and complications in cirrhotic and non-cirrhotic patients

\begin{tabular}{|c|c|c|c|c|c|}
\hline Variables & $n$ & Cirrhosis & $n$ & Non-cirrhosis & $P$ value \\
\hline \multicolumn{6}{|l|}{ Primary outcome } \\
\hline One-year mortality & 60 & $13(22)$ & 310 & $24(8)$ & 0.002 \\
\hline Five-year mortality & 60 & $22(37)$ & 310 & $55(18)$ & 0.001 \\
\hline Ten-year mortality & 60 & $24(40)$ & 310 & $63(20)$ & 0.001 \\
\hline \multicolumn{6}{|l|}{ Secondary outcomes } \\
\hline In-hospital mortality & 60 & $9(15)$ & 310 & $15(5)$ & 0.05 \\
\hline 30-day mortality & 60 & $5(8.3)$ & 310 & $12(3.9)$ & 0.18 \\
\hline CVICU LOS, days & 60 & $5[3-11]$ & 309 & $2[1-4]$ & $<0.001$ \\
\hline Any major complications & 60 & $38(63)$ & 310 & $148(48)$ & 0.02 \\
\hline Cardiac complications & 60 & $22(36.7)$ & 310 & $87(28)$ & 0.21 \\
\hline Cardiac tamponade & 60 & $2(3.3)$ & 310 & $13(4.2)$ & 0.80 \\
\hline Reoperation & 60 & $12(20)$ & 310 & $69(22.3)$ & 0.67 \\
\hline Cardiac arrest & 60 & $5(8.3)$ & 310 & $4(1.3)$ & 0.006 \\
\hline Atrial fibrillation & 60 & $14(23.3)$ & 310 & $52(16.8)$ & 0.25 \\
\hline Respiratory complications & 60 & $31(51.7)$ & 310 & $85(27)$ & $<0.001$ \\
\hline Intubation days & 60 & $2[1-5]$ & 310 & $1[0.5-1.2]$ & $<0.001$ \\
\hline Prolonged ventilation $(>24 \mathrm{hr})$ & 60 & $20(33)$ & 310 & $67(22)$ & 0.05 \\
\hline Pneumonia & 60 & $14(23.3)$ & 310 & $30(9.7)$ & 0.004 \\
\hline Pleural effusion & 60 & $9(15)$ & 310 & $16(5)$ & 0.009 \\
\hline Chest tube insertion & 60 & $6(10)$ & 310 & $10(3)$ & 0.02 \\
\hline ARDS & 60 & $4(6.7)$ & 310 & $18(5.8)$ & 0.76 \\
\hline Neurological complications & 60 & $2(3.3)$ & 310 & $14(5)$ & 0.65 \\
\hline Delirium & 60 & $2(3.3)$ & 310 & $14(4.5)$ & 0.65 \\
\hline Renal complications & 60 & $14(23.3)$ & 310 & $29(9)$ & 0.003 \\
\hline Acute kidney injury & 60 & $13(21.7)$ & 310 & $24(7.7)$ & 0.001 \\
\hline Postoperative renal replacement therapy & 60 & $9(15)$ & 310 & $19(6)$ & 0.02 \\
\hline Gastrointestinal complications & 60 & $5(8.3)$ & 310 & $17(6)$ & 0.36 \\
\hline Bleeding & 60 & $5(8.3)$ & 310 & $13(4.2)$ & 0.15 \\
\hline Mesenteric ischemia & 60 & 0 & 310 & $3(1)$ & 0.29 \\
\hline Infectious complications & 60 & $4(6.7)$ & 310 & $27(9)$ & 0.80 \\
\hline Superficial wound infection & 60 & $3(5)$ & 310 & $14(4.5)$ & 0.91 \\
\hline Deep sternal wound infection & 60 & $1(1.7)$ & 310 & $5(1.6)$ & 1.00 \\
\hline Harvest site infection & 60 & $1(1.7)$ & 310 & $10(3.2)$ & 0.5 \\
\hline UTI & 60 & 1 (1.6) & 310 & $3(1)$ & 0.65 \\
\hline
\end{tabular}

Values presented as median [interquartile range] and proportion (percentage). ARDS $=$ acute respiratory distress syndrome; CVICU $=$ cardiovascular intensive care unit; LOS = length of stay; UTI = urinary tract infection.

median MELD scores, our study shows in-hospital and tenyear mortality rates in patients with liver cirrhosis undergoing cardiac surgery were significantly higher than a propensity matched non-cirrhotic control population.

In patients with cirrhosis, cardiac surgery is associated with a higher likelihood of postoperative complications. A retrospective analysis by Hayashida et al. of 18 cirrhotic patients reports the association between cirrhosis and development of major postoperative complications such as infection, gastrointestinal bleeding, pleural effusion, and renal and respiratory failure after cardiac surgery. ${ }^{9}$ Another retrospective case analysis in 2005 showed high rates of postoperative sternal wound infections, hepatic decompensation, bacteremia, and massive bleeding in cirrhotic patients. ${ }^{27}$ Occurrence of pulmonary, renal, and infectious complications were also reaffirmed in two other retrospective cohort studies in $2011^{28}$ and $2013 .^{29}$ More recently, a systematic review in 2015 showed that cirrhosis is associated with a higher incidence of acute kidney injury and sepsis following cardiac surgery. ${ }^{1}$ Nevertheless, none 
Table 4 Multivariable analysis for the independent association of factors with increased mortality in propensity matched cirrhotic and noncirrhotic patients

\begin{tabular}{|c|c|c|c|c|c|c|}
\hline & \multicolumn{3}{|l|}{ Univariate } & \multicolumn{3}{|c|}{$\begin{array}{l}\text { Multivariate } \\
\text { AUROC: } 0.71\end{array}$} \\
\hline & Odds ratio & $95 \% \mathrm{CI}$ & $P$ value & Odds ratio & $95 \% \mathrm{CI}$ & $P$ value \\
\hline Cirrhosis & 2.7 & 1.48 to 5.03 & 0.001 & 2.2 & 1.14 to 4.12 & 0.02 \\
\hline Any transfusion & 3.7 & 2.06 to 6.8 & 0.0001 & 3.2 & 1.64 to 6.3 & 0.001 \\
\hline Number of blood products & 1 & 1.00 to 1.02 & 0.03 & 0.99 & 0.98 to 1.01 & 0.86 \\
\hline Cardiopulmonary bypass time & 1.004 & 1.00 to 1.00 & 0.02 & 1.001 & 0.99 to 1.00 & 0.63 \\
\hline
\end{tabular}

Values reported as unadjusted odds ratio (univariate) and adjusted odds ratio (multivariate) with $95 \%$ confidence interval. AUROC $=$ area under the receiver operator curve; $\mathrm{CI}=$ confidence interval.

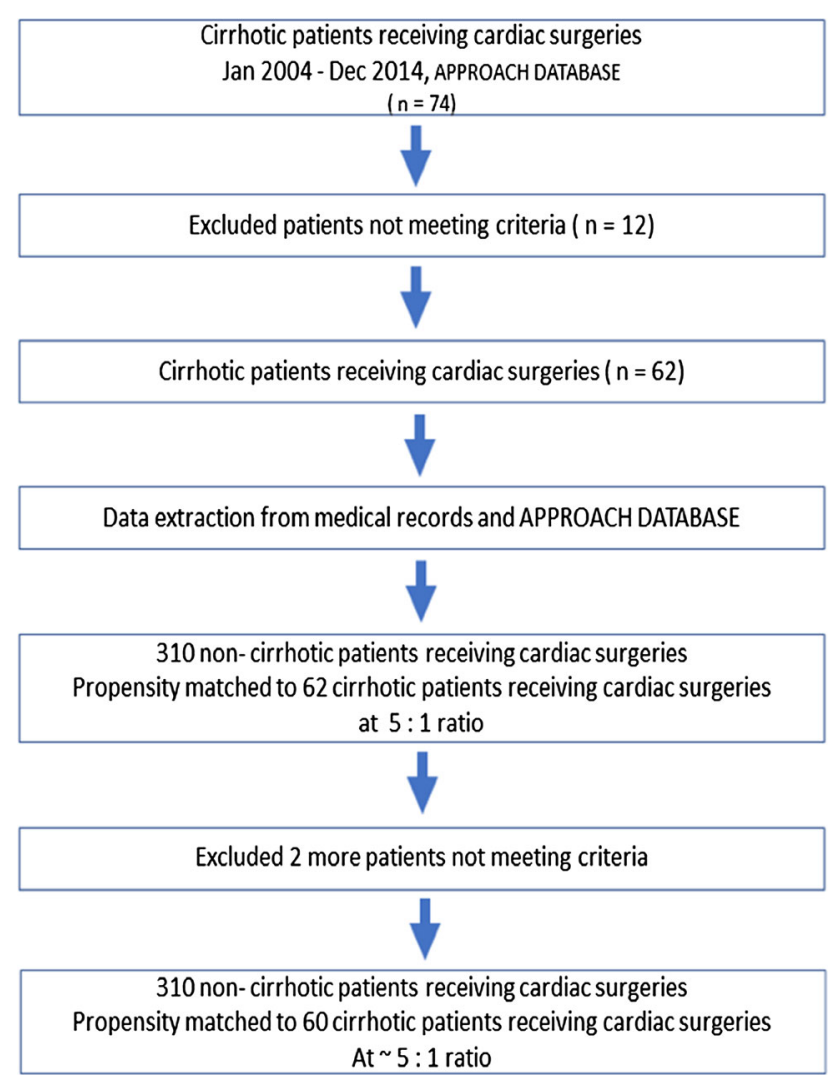

Figure Patient selection flow diagram. APPROACH: Alberta Provincial Project for Outcomes Assessment in Coronary Heart Disease.

of the above-mentioned studies included a matched control population. In our propensity score-matched analysis, we showed that cirrhosis was associated with an over two-fold increase in ten-year mortality along with increased incidence rates of postoperative complications such as cardiac arrest, pneumonia, pleural effusion, and acute kidney injury. Potentially as a consequence of increased rates of postoperative complications, existing literature consistently reports longer in-hospital and ICU stays and greater healthcare expenditure in cirrhotic patients. ${ }^{30-32}$ This was reaffirmed by our study with a matched control cohort by recording significantly longer in-hospital and ICU stays, prolonged mechanical ventilation, and increased requirement for renal replacement therapy in cirrhotic patients compared with non-cirrhotic controls.

Several studies have shown that factors such as Euroscore, MELD, central venous pressure, and CABG status were independently associated with increased mortality in cirrhotic patients undergoing cardiac surgery. In 2012, Arif et al. showed that the Euroscore and MELD score were associated with increased overall mortality in cirrhotic patients undergoing $\mathrm{CPB}$ requiring cardiac surgery. ${ }^{33}$ A year later, Lopez-Delgado et al. showed that central venous pressure is also independently associated with short-term mortality in cirrhotic cardiac surgery patients. $^{25}$ In a later report, Lin et al. showed that preoperative bilirubin and CABG status were independently associated with early and late mortality. ${ }^{26}$ In our study, although the median MELD score for the cirrhosis cohort was low (median $\sim 11$ ), the median MELD was higher in non-survivors than in survivors.

An additional observation made in our study was that patients with cirrhosis who had an intraoperative/ perioperative necessity for an increased number of blood products were at greater risk for increased ten-yearmortality. This was in agreement with a report in 2008 that showed independent association between the need for blood transfusion and increased mortality after cardiac surgery $^{34}$ and a large multicentre cohort study in 2014, which described that receiving one or two units of blood was independently associated with increased mortality after on-pump coronary artery bypass surgery. ${ }^{35}$

\section{Limitations}

The results of this study need to be considered within the context of the following limitations. Our study was a 
single-centred observational study with a limited sample size. Retrospective studies all include important sources of bias including the likelihood of residual confounding. In our institution, cardiac surgeries are performed based on the cardiac surgeon's discretion and variation in practices may have made our sample prone to selection bias. To control for operator-dependent variables, we performed post hoc analyses to determine if there were statistically significant differences between the cirrhosis/non-cirrhosis perioperative variables (surgeon, pump-time, cross-clamp time, and perioperative transfusions). While there were significant differences between the groups in pump-time and number of transfusions, adjusting for these variables (Table 4) did not significantly alter our findings. The majority of cirrhotic patients undergoing cardiac surgery had low MELD scores (only nine patients out of 60 had MELD scores $>20$ ), which may be appropriate in the surgical setting but may also introduce selection bias. To try and limit selection bias, we performed a propensity score matching with non-cirrhotic patients. ${ }^{36}$ We did not have data for international normalized ratio, bilirubin, and creatinine in patients without cirrhosis to compare the intraoperative bleeding rates in patients with cirrhosis. We did not have data on patients with cirrhosis who did not undergo cardiac surgery to provide a comparison of longterm survival in patients with cirrhosis who underwent cardiac surgery. Finally, data regarding cause of death in cirrhotic patients who died post-hospital discharge or from the APPROACH database for propensity matched noncirrhotic controls were unavailable.

\section{Conclusion}

This propensity score-matched study shows that cirrhotic patients undergoing cardiac surgery have a $40 \%$ ten-year mortality incidence. Cirrhosis was independently associated with a two-fold increase in ten-year mortality after adjusting for covariates. Further research should focus on the identification of clinically important cut-offs of preoperative parameters, which may allow a more accurate prognosis to be presented to patients with cirrhosis who face potential cardiac surgery.

Conflict of interest All authors have no personal or funding conflicts of interest.

Editorial responsibility This submission was handled by Dr. Philip M. Jones, Associate Editor, Canadian Journal of Anesthesia.

Author contributions Sheela Xavier and Constantine J. Karvellas contributed to all aspects of this manuscript, including study conception and design; acquisition, analysis, and interpretation of data; and drafting the article. Colleen M. Norris contributed to the analysis of data, and revised the final manuscript. Sean M. Bagshaw and Sean van Diepen contributed to study design, and revised the final manuscript. Amanda Ewasiuk, Demetrios J. Kutsogiannis, Derek R. Townsend, and Jayan Negendran revised the final manuscript.

Funding None.

\section{References}

1. Lopez-Delgado JC, Esteve F, Javierre C, et al. Influence of cirrhosis in cardiac surgery outcomes. World J Hepatol 2015; 7 : 753-60.

2. Hayashida N, Aoyagi S. Cardiac operations in cirrhotic patients. Ann Thorac Cardiovasc Surg 2004; 10: 140-7.

3. Shaheen AA, Kaplan GG, Hubbard JN, Myers RP. Morbidity and mortality following coronary artery bypass graft surgery in patients with cirrhosis: a population-based study. Liver Int 2009; 29: 1141-51.

4. Gopaldas RR, Chu D, Cornwell LD, et al. Cirrhosis as a moderator of outcomes in coronary artery bypass grafting and off-pump coronary artery bypass operations: a 12-year population-based study. Ann Thorac Surg 2013; 96: 1310-5.

5. Wannhoff A, Hippchen T, Weiss CS, et al. Cardiac volume overload and pulmonary hypertension in long-term follow-up of patients with a transjugular intrahepatic portosystemic shunt. Aliment Pharmacol Ther 2016; 43: 955-65.

6. Lima B, Nowicki ER, Miller CM, Hashimoto K, Smedira NG, Gonzalez-Stawinski GV. Outcomes of simultaneous liver transplantation and elective cardiac surgical procedures. Ann Thorac Surg 2011; 92: 1580-4.

7. Dimarakis I, Grant S, Corless R, et al. Impact of hepatic cirrhosis on outcome in adult cardiac surgery. Thorac Cardiovasc Surg 2015; 63: 58-66.

8. Klemperer JD, Ko W, Krieger KH, et al. Cardiac operations in patients with cirrhosis. Ann Thorac Surg 1998; 65: 85-7.

9. Hayashida $N$, Shoujima $T$, Teshima $H$, et al. Clinical outcome after cardiac operations in patients with cirrhosis. Ann Thorac Surg 2004; 77: 500-5.

10. Suman A, Barnes DS, Zein NN, Levinthal GN, Connor JT, Carey $W D$. Predicting outcome after cardiac surgery in patients with cirrhosis: a comparison of Child-Pugh and MELD scores. Clin Gastroenterol Hepatol 2004; 2: 719-23.

11. Gundling F, Seidl H, Gansera L, et al. Early and late outcomes of cardiac operations in patients with cirrhosis: a retrospective survival-rate analysis of 47 patients over 8 years. Eur J Gastroenterol Hepatol 2010; 22: 1466-73.

12. Morisaki A, Hosono M, Sasaki Y, et al. Risk factor analysis in patients with liver cirrhosis undergoing cardiovascular operations. Ann Thorac Surg 2010; 89: 811-7.

13. Macaron C, Hanouneh IA, Suman A, Lopez R, Johnston D, Carey $W W$. Safety of cardiac surgery for patients with cirrhosis and Child-Pugh scores less than 8. Clin Gastroenterol Hepatol 2012; 10: 535-9.

14. Jacob KA, Hjortnaes J, Kranenburg G, de Heer F, Kluin J. Mortality after cardiac surgery in patients with liver cirrhosis classified by the Child-Pugh score. Interact Cardiovasc Thorac Surg 2015; 20: 520-30.

15. Southern DA, Norris CM, Quan H, et al. An administrative data merging solution for dealing with missing data in a clinical registry: adaptation from ICD-9 to ICD-10. BMC Med Res Methodol 2008; DOI: https://doi.org/10.1186/1471-2288-8-1. 
16. Sharma $R$, Norris $C M$, Gyenes $G$, Senaratne $M$, Bainey KR. Effect of Cardiac Rehabilitation on South Asian Individuals With Cardiovascular Disease: Results From the APPROACH Registry. Can J Cardiol 2016; 32: S397-402.

17. van Diepen S, Graham MM, Nagendran J, Norris CM. Predicting cardiovascular intensive care unit readmission after cardiac surgery: derivation and validation of the Alberta Provincial Project for Outcomes Assessment in Coronary Heart Disease (APPROACH) cardiovascular intensive care unit clinical prediction model from a registry cohort of 10,799 surgical cases. Crit Care 2014; DOI: https://doi.org/10.1186/s13054-0140651-5.

18. Kamath PS, Kim WR; Advanced Liver Disease Study Group. The model for end-stage liver disease (MELD). Hepatology 2007; 45: 797-805.

19. Singal AK, Kamath PS. Model for end-stage liver disease. J Clin Exp Hepatol 2013; 3: 50-60.

20. Rosenbaum PR, Rubin DB. Constructing a control group using multivariate matched sampling methods that incorporate the propensity score. Am Stat 1985; 39: 33-8.

21. Guo S. Propensity Score Analysis: Statistical Methods and Applications. NY: Sage Publications; 2015 .

22. Modi A, Vohra HA, Barlow CW. Do patients with liver cirrhosis undergoing cardiac surgery have acceptable outcomes? Interact Cardiovasc Thorac Surg 2010; 11: 630-4.

23. Vanhuyse F, Maureira P, Portocarrero E, et al. Cardiac surgery in cirrhotic patients: results and evaluation of risk factors. Eur $\mathrm{J}$ Cardiothorac Surg 2012; 42: 293-9.

24. Morimoto $N$, Okada K, Okita $Y$. The model for end-stage liver disease (MELD) predicts early and late outcomes of cardiovascular operations in patients with liver cirrhosis. Ann Thorac Surg 2013; 96: 1672-8.

25. Lopez-Delgado JC, Esteve F, Javierre $C$, et al. Short-term independent mortality risk factors in patients with cirrhosis undergoing cardiac surgery. Interact Cardiovasc Thorac Surg 2013; 16: 332-8.
26. Lin $\mathrm{CH}, \mathrm{Hsu} \mathrm{RB}$. Cardiac surgery in patients with liver cirrhosis: risk factors for predicting mortality. World J Gastroenterol 2014; 20: 12608-14.

27. Lin CH, Lin FY, Wang SS, Yu HY, Hsu RB. Cardiac surgery in patients with liver cirrhosis. Ann Thorac Surg 2005; 79: 1551-4.

28. Marui A, Kimura T, Tanaka S, et al. Coronary revascularization in patients with liver cirrhosis. Ann Thorac Surg 2011; 91: 13939.

29. Morimoto N, Okada K, Okita $Y$. Results of cardiac surgery in advanced liver cirrhosis. Gen Thorac Cardiovasc Surg 2013; 61: 79-83.

30. Bizouarn P, Ausseur A, Desseigne P, et al. Early and late outcome after elective cardiac surgery in patients with cirrhosis. Ann Thorac Surg 1999; 67: 1334-8.

31. Steffen RJ, Bakaeen FG, Vargo PR, et al. Impact of cirrhosis in patients who underwent surgical aortic valve replacement. Am J Cardiol 2017; 120: 648-54.

32. Araujo L, Dombrovskiy V, Kamran $W$, et al. The effect of preoperative liver dysfunction on cardiac surgery outcomes. J Cardiothorac Surg 2017; DOI: https://doi.org/10.1186/s13019017-0636-y.

33. Arif $R$, Seppelt P, Schwill $S$, et al. Predictive risk factors for patients with cirrhosis undergoing heart surgery. Ann Thorac Surg 2012; 94: 1947-52.

34. Scott BH, Seifert FC, Grimson R. Blood transfusion is associated with increased resource utilisation, morbidity and mortality in cardiac surgery. Ann Card Anaesth 2008; 11: 15-9.

35. Paone G, Likosky DS, Brewer R, et al. Transfusion of 1 and 2 units of red blood cells is associated with increased morbidity and mortality. Ann Thorac Surg 2014; 97: 87-93; discussion 93-4.

36. Walsh MC, Trentham-Dietz A, Newcomb PA, Gangnon R, Palta $M$. Using propensity scores to reduce case-control selection bias. Epidemiology 2012; 23: 772-3.

Publisher's Note Springer Nature remains neutral with regard to jurisdictional claims in published maps and institutional affiliations. 